\title{
Effects of clear-cutting and wildfires on succession of ground beetle (Coleoptera: Carabidae) assemblages on the east slopes of the Rocky Mountains
}

\author{
Vincent Del Bel Belluz ${ }^{\ddagger}$, David Langor ${ }^{\S}$, Jari Niemeläl, John R. Spence ${ }^{\ddagger}$ \\ ‡ University of Alberta, Edmonton, Canada \\ $\S$ Natural Resources Canada, Edmonton, Canada \\ | University of Helsinki, Department of Environmental Sciences, Helsinki, Finland
}

Corresponding author: Vincent Del Bel Belluz (vbelluz@gmail.com)

Received: 15 Aug 2019 | Published: 16 Aug 2019

Citation: Del Bel Belluz V, Langor D, Niemelä J, Spence JR (2019) Effects of clear-cutting and wildfires on succession of ground beetle (Coleoptera: Carabidae) assemblages on the east slopes of the Rocky Mountains. ARPHA Conference Abstracts 2: e39118. https://doi.org/10.3897/aca.2.e39118

\section{Abstract}

We studied how carabid beetle assemblages in lodgepole pine stands have responded after clear-cut harvest and wildfires on an actively managed landscape $\sim 20 \mathrm{~km}$ south of Hinton, Alberta, Canada. The work builds on and expands a previous study (Niemela et al. 1993) conducted 23-24 years earlier in many of the same stands sampled in the current study. Carabid species assemblages are compared along a chronosequence of stands ranging in age from 12 to 53 years after clear-cutting. Recovery of carabid assemblages toward pre-harvest structure in regenerating stands, as reflected in the 2013-14 data, appears to have progressed more rapidly than in equivalently aged stands from the earlier study. In addition, carabid species assemblages differed significantly between clear-cut and burned stands of comparable age in 2013-14, with assemblages of burned stands being more similar to the pre-harvest structure than in clear-cut stands. Ground vegetation, mineral soil cover and basal area of trees and shrubs were significantly correlated with structure of carabid species assemblages in young and old regenerating stands, suggesting that environmental and plant successional gradients drive patterns in carabid 
assemblages. However, assemblage differences between older burned and clear-cut stands indicate that the type of disturbance influences long-term carabid recovery. Relationships between these findings and issues related to conservation of biodiversity and climate change are discussed.

\section{Presenting author}

Vincent Del Bel Belluz

\section{Presented at}

19thECM oral communication

\section{References}

- $\quad$ Niemela J, Langor D, Spence J (1993) Effects of Clear-Cut Harvesting on Boreal GroundBeetle Assemblages (Coleoptera: Carabidae) in Western Canada. Conservation Biology 7 (3): 551-561. https://doi.org/10.1046/j.1523-1739.1993.07030551.x 